\title{
Portuguese-speaking African countries face shortages of doctors
}

Published at www.cmaj.ca on July 9

I t's often problematic enough to train doctors to practise in the developing world.

Add language to the equation and a chronic shortage of physicians can become a crisis.

So it seems in five Portuguesespeaking nations of Africa - Angola, Cape Verde, Guinea Bissau, Mozambique, São Tomé and Príncipe which are struggling to cope with inadequate production of physicians and a brain drain, while facing escalating domestic demands for health care workers, according to a new report.

The former colonies of Portugal don't have the indigenous capacity to produce enough doctors, while natives of those five countries who go abroad for medical training often opt not to return home to practise, adds the report, Analysis of Human Resources for Health in African Portuguese Speaking Countries.

The number of physicians in the former colonies is grim, according to the World Health Organization report coauthored by Gilles Dussault and Dr. Inês Fronteira of the Lisbon, Portugalbased Institute of Hygiene and Tropical Medicine (www.who.int/hrh/resources /observer2/en/index.html).

The report indicates that the number of physicians in Angola is 0.0077 per 10000 inhabitants, while its 4.5 in Cape Verde and 5.0 in São Tomé and Príncipe. Mozambique and Guinea-Bissau, meanwhile, have respective figures of 0.44 and 0.98 physicians per 10000 population. By comparison, there are 34 physicians per 10000 inhabitants in Portugal, according to the European Observatory on Health Systems and Policies.

The low numbers in the former colonies appear in part the product of limited domestic capacity to train physicians. Angola has just two medical

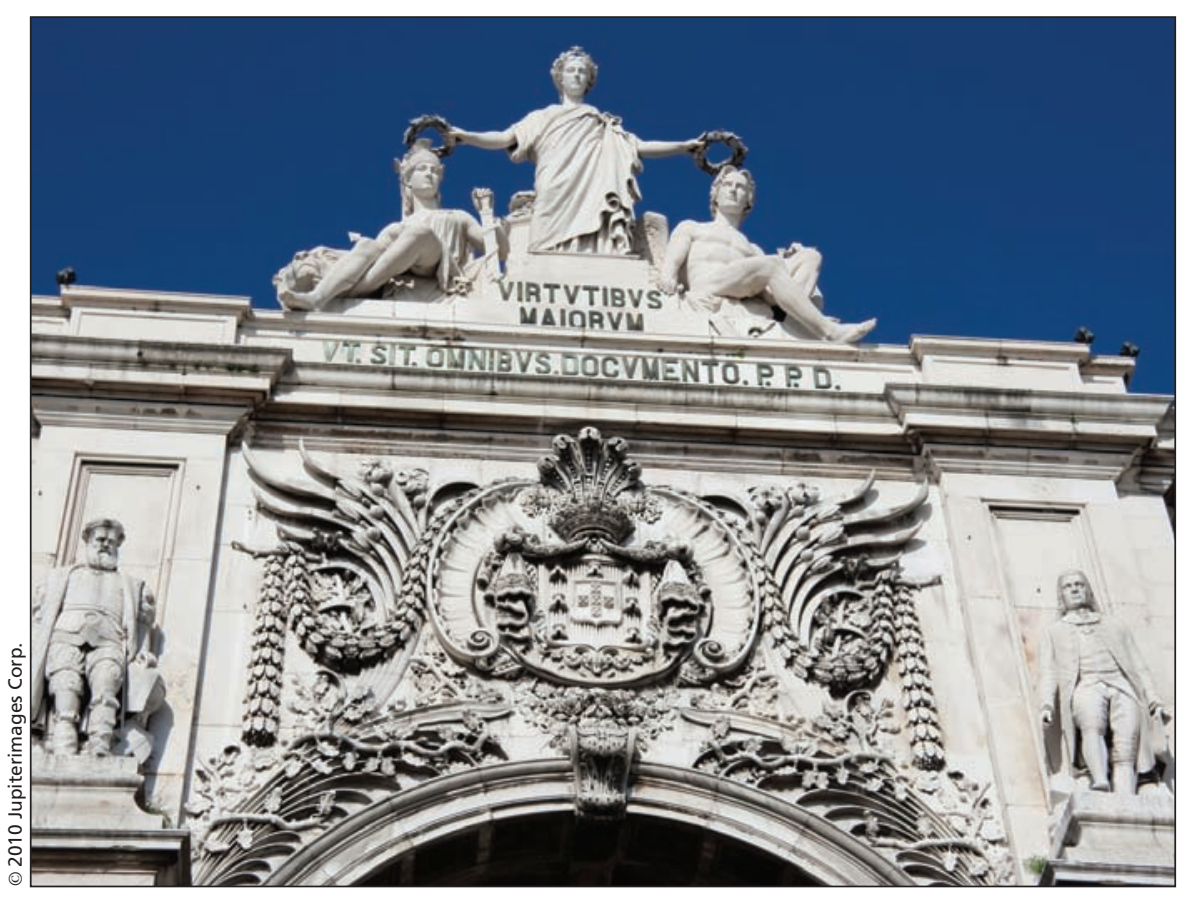

The triumphal arch at the square of commerce in Lisbon, Portugal was intended to honour Portuguese glories but five former colonies are finding that they have physician shortages and do not have the indigenous capacity to produce enough doctors.

schools and Mozambique just three, while Guinea-Bissau has but one. Both Cape Verde and São Tomé and Príncipe have none and those interested in becoming physicians typically pursue their studies in Portugal, Brazil or Cuba.

But the brain drain is not uniform among the five former colonies and may not be significant in quantitative terms. As Dr. Mario Dal Poz, coordinator of human resources of health at WHO notes, "the amount here is in absolute terms, meaning that if none of the countries has too many doctors, the total amount of doctors leaving is not very big."

Emigration of physicians seems to be a larger problem in Cape Verde and São Tomé and Príncipe, where the absence of medical schools requires prospective doctors to study and train abroad. Many end up not returning. Yet even Mozambique, which is apparently the country least affected by the drain of doctors, faces increased emigration of physicians to South Africa and Portugal, according to a World Bank report (www.biomedcentral.com/content/pdf /1478-4491-5-11.pdf ).

The latest analysis indicates that the five Portuguese-speaking nations of Africa face an excessive dependency on foreign physicians. They now comprise $30.8 \%$ of physicians in Mozambique, $23.2 \%$ in Angola and 16\% in Cape Verde. (Figures for Guinea-Bissau and São Tomé and Príncipe were unavailable).

Still, Dussault is optimistic about the future.

"There is a growing commitment in PALOP [Países Africanos de Língua Oficial Portuguesa] countries to scaling-up training capacity and recognition of the need to enhance retention capacity," he writes in an email. "It is the case of Angola and Mozambique 
where enormous efforts have been made to create more faculties of medicine and other health schools, not only in the capital city, but also in the provinces. Moreover, countries are developing several strategies to deal with it: they choose the best students to pursue an academic career, or at least, to remain linked to Medical Schools. They received the help of foreign teachers that at the same time train students and professors, or they use new information technologies."

To resolve the shortages of health care workers, the report urges collaborative action.

An example would be the exchange of trainers between countries, Frontiera writes in an email. Guinea Bissau has developed a "costing tool" for health human resources that could be a bench- mark for other nations, while there's a joint project in the pipeline to train teachers for technical schools, which produce radiologists, radio therapists and laboratory technicians. As well, a program will be launched this fall by the European Commission and WHO to enhance management training.

Dussault writes the solutions must begin with improvements to medical training, particularly through the use of distance learning at medical schools.

"As for stopping the brain drain, one aspect is crucial and that only the country can provide: security and good working and leaving conditions. Besides that, it is important to train doctors using context specific curricula, to guarantee salaries (to ensure that medical doctors are being paid) and to develop non-financial incentives pack- ages (that include housing conditions, career opportunities and family/ educational support)," he writes.

Others say the answers lie in structural political changes at the national level. "Corruption is more damaging to health than poverty, which explains Angola's poor results," says Juan Gérvas, professor of international health and primary care at the Spanish National School of Public Health in Madrid. "On the other hand, Cape Verde is on the right path due to its accomplishments, namely democratic stability, good governance, economic development, health care workforce and general education of the population." - Tiago Villanueva MD, Lisbon, Portugal

DOI:10.1503/cmaj.109-3301 